Jurnal SPORTIF: Jurnal Penelitian Pembelajaran

Vol. 6 No. 2, Agustus 2020, pp. 364-374

doi https://doi.org/10.29407/js_unpgri.v6i2.14360

\title{
Efektivitas senam vitalisasi otak terhadap kebugaran jasmani pada lansia demensia
}

\section{Effectiveness of the brain vitality exercise on physical fitness in elderly with dementia}

\author{
Mustika Fitri ${ }^{1}$, Upik Rahmi ${ }^{2}$, Pipit Pitriani ${ }^{3}$, dan Afianti Sulastri ${ }^{4}$ \\ ${ }^{1}$ Department of Sports Science, Faculty of Sports and Health Education, Universitas \\ Pendidikan Indonesia, Street of Dr. Setiabudi No.229 Bandung, West Java Province, \\ 40154, Indonesia \\ ${ }^{2,4}$ Department of Nursing, Faculty of Sports and Health Education, Universitas Pendidikan \\ Indonesia, Street of Dr. Setiabudi No.229 Bandung, West Java Province, 40154, \\ Indonesia \\ ${ }^{3}$ Department of Coaching EducationFaculty of Sports and Health Education, Universitas \\ Pendidikan Indonesia, Street of Dr. Setiabudi No.229 Bandung, West Java Province, \\ 40154, Indonesia
}

Received: 6 May 2020; Revised: 26 June 2020; Accepted: 7 July 2020

\begin{abstract}
Abstrak
Aktivitas fisik akan meningkatkan kebugaran jasmani sehingga dapat memperlambat perkembangan kognitif dan penurunan fisik lansia dengan demensia. Demensia merupakan sindrom neurodegeneratif yang timbul karena adanya kelainan bersifat kronis dan progesif disertai dengan gangguan fungsi luhur multipel seperti kalkulasi, kapasitas belajar, bahasa, dan mengambil keputusan. Penelitian ini bertujuan untuk mengetahui kebugaran jasmani lansia dengan demensia pasca aktivitas fisik dengan senam vitalisasi otak. Metode yang digunakan dalam penelitian ini yaitu Metode Experimental. 10 subjek yang berusia 60 - 85 tahun dengan demensia ringan diberi perlakuan senam vitalisasi otak selama 12 kali dengan durasi waktu 25 menit. Setelah melakukan aktivitas fisik dilakukan pemeriksaan tes kebugaran jasmani (testing the elderly) yang terdiri dari: 6 minutes walk test (6 MWT), flexibility: Chair seat and reach test (CSRT), Muscle strength and endurance: Chair stand test (CST), dan Arm curl test (ACT), koordinasi dan kelincahan, 8 Foot up and go test (8 FUGT). Hasil penelitian dengan menggunakan uji $\mathrm{T}$ menunjukkan bahwa tes kebugaran memberikan hasil yang signifikan pada tes CST, CSRT ( $p$ value 0,0296) dan 8 FUGT 6MWT (pvalue 0,0229) pada tingkat kepercayaan 95\%. Kesimpulannya, aktivitas fisik vitalisasi otak berpengaruh terhadap kebugaran jasmani dengan perbaikan tonus otot dan kognitif pada lansia dengan demensia.
\end{abstract}

Kata kunci: aktivitas fisik, senam vitalisasi otak, demensia, lanjut usia, tes kebugaran jasmani.

\begin{abstract}
Physical activity increases physical fitness and therefore, reduces the rate of cognitive and physical decline in elderly with dementia. Dementia is a neurodegenerative syndrome which occurs due to chronic and progressive abnormalities accompanied by multiple sublime functions such as calculations, learning capacity, language, and decision making. The aim of this study was to determine the effect of physical activity using Brain Vitality Exercises on the physical fitness of elderly with dementia. The method used in this study was
\end{abstract}

Correspondence author: Mustika Fitri, Universitas Pendidikan Indonesia, Indonesia.

Email:mustikafitri@upi.edu

Jurnal SPORTIF: Jurnal Penelitian Pembelajaran is licensed under a Creative Commons Attribution-ShareAlike 4.0 International License. 
the Experimental Method. A total of 10 subjects between the ages of 60-85 years with mild dementia, were treated using Brain Vitality Exercises for 12 times with duration of 25 minutes. Furthermore, they were tested for physical fitness (Testing The Elderly) with 6 minutes walk test (6 MWT), flexibility with Chair seat and reach test (CSRT), muscle strength and endurance with Chair stand (CST) and Arm curl test (ACT), coordination and agility with 8 Foot up and go test (8 FUGT) pre and post treatment. The results of this study showed that the fitness test produced significant results on the CST, CSRT ( $p$ value of 0.0296) and 8FUGT, 6MWT ( $p$ value of 0.0229) with a 95\% confidence level. Therefore, Brain Vitality Exercise has an effect on physical fitness with improvement in muscle tone and cognitive ability among the elderly with dementia.

Keywords: physical activity, brain vitality exercise, dementia, elderly, physical fitness tests.

\section{PENDAHULUAN}

Demensia merupakan penurunan fungsi kognitif otak yang mengganggu aktivitas sehari-hari, pelupa, gangguan pemahaman, gangguan bahasa, pembelajaran, perhitungan, dan penilaian (Seth $A$. Gale, Diler Acar, 2018; Petherbridge, 2019). Gangguan fungsi kognitif pada penyakit demensia biasanya disertai dengan memburuknya emosi, perilaku, dan motivasi, sehingga mengganggu aktivitas sehari-hari.

Salah satu pencegahan gangguan kognitif pada lansia dengan demensia adalah aktivitas fisik dengan senam vitalisasi otak, karena aktivitas fisik merupakan gerakan tubuh yang menghasilkan energi atau latihan yang telah diatur sebelumnya, disengaja, dan berulang (Ferioli et al., 2019). Aktivitas fisik memiliki efek positif tehadap fungsi kognitif, pembelajaran spasial dan memori, untuk menjaga kesehatan otak dan mengobati neurodegeneratif dan/atau kejiwaan kondisi dengan latihan aerobik dan resistensi pada populasi dewasa dan usia lanjut (Cassilhas, Tufik, \& De Mello, 2016). Aktivitas fisik dengan irama musik dan improvisasi musik juga dapat meningkatkan fungsi kognitif pada lansia dengan gangguan kognitif ringan-sedang (Biasutti \& Mangiacotti, 2018; Van Alphen, Hortobágyi, \& van Heuvelen, 2016). Dimana Aktivitas fisik yang dilakukan selama 35 menit memiliki implikasi responsif Brain-derived neurotrophic factor (BDNF) (Håkansson et al., 2017; Gonçalves, Marques, Samuel, \& Demain, 2019). Kurangnya aktivitas fisik merupakan faktor 
risiko indepeden untuk penyakit kronis dan secara keseluruhan diperkirakan dapat menyebabkan kematian secara global.

Meninjau dari penelitian sebelumnya yang meneliti tentang pengaruh aktivitas fisik terhadap fungsi kognitif pada pasien dengan demensia (Groot et al., 2016), durasi tidur, penurunan kognitif dan risiko demensia pada wanita yang lebih tua (Chen et al., 2016), serta aktivitas fisik dan demensia pada kembar dewasa (Iso-Markku, Waller, Kujala, \& Kaprio, 2015), peneliti belum menemukan adanya penelitian tentang efektivitas senam vitalisasi otak dengan durasi yang sudah ditentukan terhadap kebugaran jasmani pada lansia demensia. Sebagaimana rekomendasi dari hasil penelitian Paillard (2015) yang menyatakan bahwa untuk penelitian selanjutnya tentang aktivitas fisik untuk demensia perlu difokuskan terkait durasi pelaksanaannya.

Oleh karena itu tujuan dari penelitian ini didasari pada kebutuhan keilmuan untuk meneliti kebugaran jasmani lansia demensia pasca aktivitas fisik dengan senam vitalisasi otak yang durasinya telah ditentukan. Penelitian ini merupakan keterbaruan dari penelitian-penelitian terdahulu dan harus dilakukan karena penting untuk menguji seberapa besar dampak senam vitalisasi otak terhadap kebugaran jasmani pada lansia demensia. Selain itu hasil dari penelitian ini dapat menjadi referensi untuk seseorang atau kelompok dalam melakukan aktivitas fisik pada lansia demensia. Karena pada dasarnya penting dalam mengetahui aktivitas fisik yang bisa diterapkan terhadap lansia demensia untuk menguji kebugaran jasmaninya (Hesseberg, Bentzen, Ranhoff, Engedal, \& Bergland, 2016).

\section{METODE}

Penelitian ini menggunakan metode quasi eksperimental dengan pendekatan one group pretest-posttest design untuk mengetahui pengaruh yang timbul, sebagai akibat dari adanya perlakuan aktivitas fisik terhadap tes kebugaran pada lansia dengan demensia ringan. Populasi dalam penelitian ini berjumlah 30 orang lansia yang mengalami demensia yang berasal dari kecamatan Cibeunying Kidul, Kelurahan Padasuka, 
yang dikelola oleh POSBINDU (Pos Binaan Terpadu) bernama Tanjung. Setelah melalui seleksi MMSE (Mini-Mental Status Examination) berdasarkan kriteria inklusi dengan syarat yaitu lansia dan skor MMSE < 23 (Monroe \& Carter, 2012), maka terpilihlah sebanyak 10 orang dengan kriteria inklusi yaitu lansia dengan demensia ringan. Sampel yang terpilih berumur antara 60-85 tahun. Intervensi senam vitalisasi otak diberikan kepada lansia dengan demensia ringan selama 12 perlakuan dengan durasi waktu setiap senam 25 menit.

Pengukuran kebugaran jasmani menggunakan instrumen tes kebugaran jasmani (testing the elderly) yang terdiri dari: 1. Cardiorespiratory endurance: 6 minute walk test (6 MWT), 2. flexibility: Chair seat and reach test (CSRT), 3. Muscle strength and endurance: Chair stand test (CST) dan Arm curl test (ACT), dan 4. Koordinasi dan kelincahan: 8 Foot up and go test (8 FUGT).

Dalam menentukan sampel, peneliti menggunakan MMSE (MiniMental Status Examination). Scoring untuk menentukan lansia dengan demensia ringan dimana skornya yaitu <23 (Monroe \& Carter, 2012). Pemeriksaan MMSE adalah tes yang paling sering dipakai saat ini. Penilaian dengan nilai maksimal 30 , cukup baik dalam mendeteksi gangguan kognitif, menetapkan data dasar dan memantau penurunan kognitif dalam kurun waktu tertentu (Folstein, Folstein, \& Mchugh, 1975). Setelah melakukan pemeriksaan MMSE, yang mendapatkan skor <23 yaitu sebanyak 10 orang lansia. Namun sebelum menjalani tes, peneliti menjelaskan maksud dan tujuan diadakannya penelitian ini. Setelah sampel memahami penjelasan peneliti dan bersedia mengikuti serangkaian item test, sampel didata sesuai nama, usia, dan jenis kelamin. Sampel terlebih dahulu di cek denyut nadi untuk mengetahui kondisi kesehatannya sebelum menjalankan tes. Langkah selanjutnya mulai dilakukan beberapa item test yang telah disiapkan peneliti yaitu 6 Minute Walk Test (6 MWT), Chair Seat and Reach Test (CSRT), Chair Stand Test (CST), Arm Curl Test (ACT), 8 Foot Up and Go Test (8 FUGT). 
Langkah awal yang dilakukan peneliti dalam menganalisis data yaitu menguji terlebih dahulu setiap data pada item test dengan uji normalitas data menggunakan Kolmogorov Smirnov. Setelah data dinyatakan normal, peneliti menganalisis data menggunakan Paired Samples $t$ - test untuk melihat perbedaan rata - rata dari pretes dan posttest yang berasal dari subjek yang sama (Pallant, 2010). Program Statistical Product for Social Science (SPSS) Statistics versi 22 dipilih oleh peneliti untuk menganalisis data pada penelitian ini.

\section{HASIL}

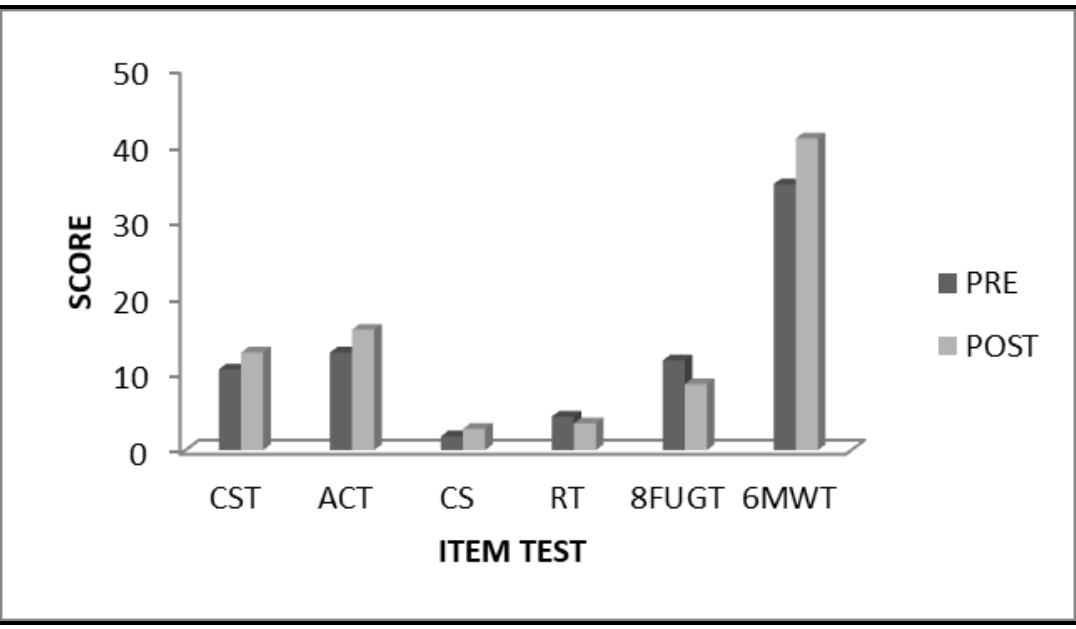

Gambar 1. Skor Tes Kebugaran Pretest dan Posttest Setiap Item Test

Secara umum, terdapat peningkatan skor kebugaran pada lansia demensia antara sebelum dan sesudah perlakuan, terutama pada item tes CST, ACT, 8FUGT dan 6MWT.

Tabel 1. Hasil Tes Kebugaran Pretest dan Posttest Setiap Item Test

\begin{tabular}{|c|c|c|c|}
\hline \multirow{2}{*}{ ITEM TEST } & PRE & POST & \multirow{2}{*}{$p$-Value } \\
\hline & \multicolumn{2}{|c|}{$M \pm S D$} & \\
\hline CST (s) & $10.60 \pm 4.62$ & $12.80 \pm 4.8$ & $0.006^{*}$ \\
\hline$A C T(\mathrm{~s})$ & $12.80 \pm 5.01$ & $15.80 \pm 4.37$ & $0.013^{*}$ \\
\hline$C S(\mathrm{~cm})$ & $1.80 \pm 7.04$ & $2.80 \pm 2.66$ & 0.591 \\
\hline$R T(\mathrm{~cm})$ & $4.40 \pm 5.68$ & $3.50 \pm 3.21$ & 0.507 \\
\hline 8FUGT (s) & $11.76 \pm 7.27$ & $9.05 \pm 4.73$ & $0.012^{*}$ \\
\hline $6 M W T(\mathrm{~m})$ & $348.90 \pm 82.96$ & $409.10 \pm 100.09$ & $0.028^{*}$ \\
\hline
\end{tabular}

* Signifikansi different $p<0.05$

Tabel 1. menunjukkan nilai rata-rata pretest dari Chair Stand Test (CST) yaitu 10.60 dengan standar deviasi 4.62 sedangkan nilai rata - rata 
posttest-nya yaitu 12.80 dengan standar deviasi 4.80. Pada nilai rata-rata pretest dari Arm Curl Test (ACT) yaitu 12.80 dengan standar deviasi 5.00666, sedangkan nilai rata-rata posttest-nya yaitu 15.80 dengan standar deviasi 4.37. Pada nilai rata-rata pre test dari Chair Seat (CS) yaitu 1.8000 dengan standar deviasi 7.04 , sedangkan nilai rata-rata posttest-nya yaitu 2.80 dengan standar deviasi 2.66. Pada nilai rata-rata pretest dari Reach Test (RT) yaitu 4.40 dengan standar deviasi 5.68, sedangkan nilai rata-rata posttest-nya yaitu 3.50 dengan standar deviasi 3.21. Pada nilai rata-rata pretest dari 8 Foot Up and Go Test (8 FUGT) yaitu 11.76 dengan standar deviasi 7.27 , sedangkan nilai rata-rata posttest-nya yaitu 9.05 dengan standar deviasi 4.73. Pada nilai rata-rata pretest dari 6 Minute Walk Test (6 MWT) yaitu 348.90 dengan standar deviasi 82.96, sedangkan nilai rata-rata posttest-nya yaitu 409.10 dengan standar deviasi 100.09.

Pemberian perlakuan senam kepada 10 orang lansia demensia berpengaruh signifikan terhadap Chair stand test (CST) dengan Sig. 0.006, Arm curl test (ACT) dengan Sig. 0.013, 8 Foot up and go test (8 FUGT) dengan Sig. 0.012 dan 6 minute walk test (6 MWT) dengan Sig. 0.028 pada tingkat kepercayaan $95 \%$.

\section{PEMBAHASAN}

Hasil penelitian ini menunjukkan bahwa tes kebugaran Chair stand test (CST) dan Arm curl test (ACT) dan tes 8 Foot up and go test (8 FUGT) dan 6 minute walk test (6 MWT) sangat efektif dilakukan pada lansia dengan demensia, ini sejalan dengan penelitian (López-Miñarro, Sáinz De Baranda, Rodríguez-García, \& Yuste, 2008; Nakazono, Kamide, \& Ando, 2014). Tes 8 FUGT direkomendasikan untuk mengidentifikasi risiko jatuh pada lansia di masyarakat. Chair stand test (CST) dan Arm curl test (ACT) sangat efektif untuk mengukur massa otot, kekuatan dan/atau kehilangan kinerja pada wanita tua (López-Miñarro et al., 2008) dan Chair stand test (CST) dan Arm curl test (ACT), Chair seat and reach test (CSRT) menunjukkan akurat dan stabil sebagai ukuran dari hamstring flexibility pada yang lebih tua (Jones, Rikli, Max, \& Noffal, 1998). Lansia 
demensia mengalami penurunan masa otot dan perubahan fungsional akibat gangguan fungsi luhur, dengan diberikan perlakuan aktivitas fisik sehingga akan membantu kekuatan otot lansia (López-Miñarro et al., 2008). Tes 6 minute walk test (6 MWT) efektif pada penderita yang mengalami gangguan kognitif secara fisik dan fungsional (Pinheiro, Carneiro, Coqueiro, Pereira, \& Fernandes, 2015).

Selain perubahan tes kebugaran, aktivitas fisik juga memberikan dampak positif terhadap perbaikan memori lansia demensia. Hasil ini sejalan dengan hasil penelitian Farrow \& Ellis (2013) bahwa orang dewasa yang melakukan aktivitas fisik secara teratur memiliki risiko penurunan kemampuan kognitif dan pengembangan demensia yang lebih rendah, dibandingkan dengan mereka yang tidak aktif. Hal ini dikarenakan gangguan kognitif pada lansia dengan demensia perlu dilakukan aktivitas fisik untuk perlindungan saraf dan kinerja kognitif yang menunjukkan efek positif dengan program latihan yang terstruktur, individual, intensitas lebih tinggi, durasi lebih lama, dan multikomponen (Kirk-Sanchez \& McGough, 2013).

Penelitian ini juga didukung oleh penelitan Jin dkk. (2018) bahwa irisin dan miokin yang disekresikan otot rangka, diproduksi sebagai respons terhadap latihan fisik, memiliki fungsi perlindungan di sistem saraf pusat dan perifer, termasuk regulasi faktor neurotropik yang diturunkan dari otak. Secara khusus, irisin mampu melindungi hippocampus karena daerah ini adalah wilayah otak yang paling rentan terhadap penyakit demensia, efek menguntungkan tersebut dapat menghambat atau menunda munculnya penyakit neurodegeneratif, termasuk alzheimer demensia. Latihan fisik (Aktivitas otot) berdampak tidak hanya pada adaptasi sirkulasi, tetapi juga integrasi neuron dengan potensi untuk mempengaruhi kognisi (Fernandes et al., 2018). Efek latihan fisik pada pemulihan kognitif menunjukkan penilaian kognitif yang lebih baik (Morris, Osman, Muñoz, Costa-Miserachs, \& Leone, 2016).

Fungsi kognitif merupakan fungsi yang kompleks pada otak manusia yang melibatkan aspek memori, baik jangka pendek atau memori 
jangka panjang, perhatian, fungsi perencanaan dan nalar serta fungsi strategi dalam berfikir dari seseorang, seperti bahasa dan pembendaharaan kata. Gangguan fungsi kognitif merupakan gangguan fungsi utama pada otak berupa gangguan pada orientasi, perhatian, kosentrasi, daya ingat (memori), dan bahasa, serta pada gangguan fungsi intelektual akan terlihat dengan adanya gangguan dalam berhitung, bahasa, daya ingat semantik (kata-kata), dan pemecahan masalah pada seseorang. fungsi kognitif dapat terjadi pada penyakit demensia (Scheltens et al., 2017). Penyakit demensia diawali dan disertai dengan adanya kemrosotan (deterioration) dalam pengendalian emosi, perilaku sosial, atau motivasi hidup pada penderita demensia (Phung et al., 2017).

\section{KESIMPULAN DAN SARAN}

Aktivitas fisik senam vitalisasi otak memberikan dampak positif terhadap kebugaran jasmani sehingga perbaikan memori lansia demensia dimana aktivitas fisik secara teratur memiliki risiko penurunan kemampuan kognitif dan pengembangan demensia yang lebih rendah, dibandingkan dengan mereka yang tidak aktif. Diharapkan pada penelitian selanjutnya dapat di temukan suatu senam khusus untuk lansia yang didalam gerakannya mengandung unsur tes kebugaran jasmani lansia, sehingga didapatkan angka kebugaran jasmani dengan peningkatan yang signifikan tinggi.

\section{REFERENSI}

Biasutti, M., \& Mangiacotti, A. (2018). Assessing a cognitive music training for older participants: a randomised controlled trial. International Journal of Geriatric Psychiatry, 33(2), 271-278. https://doi.org/10.1002/gps.4721

Cassilhas, R. C., Tufik, S., \& De Mello, M. T. (2016). Physical exercise, neuroplasticity, spatial learning and memory. Cellular and Molecular Life Sciences, 73(5), 975-983. https://doi.org/10.1007/s00018-0152102-0

Chen, J. C., Espeland, M. A., Brunner, R. L., Lovato, L. C., Wallace, R. B., Leng, X., Mysiw, W. J. (2016). Sleep duration, cognitive decline, and dementia risk in older women. Alzheimer's and Dementia, 12(1), 2133. https://doi.org/10.1016/j.jalz.2015.03.004 
Farrow, M., \& Ellis, K. (2013). Physical activity for brain health and fighting dementia. Alzheimer's Australia Incorporated. https://doi.org/10.1021/ja00475a016

Ferioli, M., Zauli, G., Maiorano, P., Milani, D., Mirandola, P., \& Neri, L. M. (2019). Role of physical exercise in the regulation of epigenetic mechanisms in inflammation, cancer, neurodegenerative diseases, and aging process. Journal of Cellular Physiology, 234(9), 1485214864. https://doi.org/10.1002/jcp.28304

Fernandes, R. M., Correa, M. G., dos Santos, M. A. R., Almeida, A. P. C. P. S. C., Fagundes, N. C. F., Maia, L. C., \& Lima, R. R. (2018). The effects of moderate physical exercise on adult cognition: A systematic review. Frontiers in Physiology, 9(JUN), 1-11. https://doi.org/10.3389/fphys.2018.00667

Folstein, M. F., Folstein, S. E., \& Mchugh, P. R. (1975). "Mini-Mental State" A Practical Method For Grading The Cognitve State of Patients for The Clinician. Journal Psychiat, 12, 189-198. https://doi.org/10.1016/0022-3956(75)90026-6

Gonçalves, A. C., Marques, A., Samuel, D., \& Demain, S. (2019). Outcomes of physical activity for people living with dementia: qualitative study to inform a Core Outcome Set. Physiotherapy (United Kingdom). https://doi.org/10.1016/j.physio.2019.05.003

Groot, C., Hooghiemstra, A. M., Raijmakers, P. G. H. M., van Berckel, B. N. M., Scheltens, P., Scherder, E. J. A., Ossenkoppele, R. (2016). The effect of physical activity on cognitive function in patients with dementia: A meta-analysis of randomized control trials. Ageing Research Reviews, 25, 13-23. https://doi.org/10.1016/j.arr.2015.11.005

Håkansson, K., Ledreux, A., Daffner, K., Terjestam, Y., Bergman, P., Carlsson, R., Mohammed, A. K. H. (2017). BDNF Responses in Healthy Older Persons to 35 Minutes of Physical Exercise, Cognitive Training, and Mindfulness: Associations with Working Memory Function. Journal of Alzheimer's Disease, 55(2), 645-657. https://doi.org/10.3233/JAD-160593

Hesseberg, K., Bentzen, H., Ranhoff, A. H., Engedal, K., \& Bergland, A. (2016). Physical fitness in older people with mild cognitive impairment and dementia. Journal of Aging and Physical Activity, 24(1), 92-100. https://doi.org/10.1123/japa.2014-0202

Iso-Markku, P., Waller, K., Kujala, U. M., \& Kaprio, J. (2015). Physical activity and dementia: Long-term follow-up study of adult twins. Annals of Medicine, 47(2), 81-87. https://doi.org/10.3109/07853890.2014.994675

Jin, Y., Sumsuzzman, D. M., Choi, J., Kang, H., Lee, S. R., \& Hong, Y. (2018). Molecular and functional interaction of the myokine irisin with physical exercise and Alzheimer's disease. Molecules, 23(12), 1-13. 
https://doi.org/10.3390/molecules23123229

Jones, C. J., Rikli, R. E., Max, J., \& Noffal, G. (1998). Cluarterly for Exercise and Sport a The Reliability and Validity of a Chair Sit-andReach Test as a Measure of Hamstring Flexibility in Older Adults. Physical Education, Recreation and Dance. \&, 69(4), 338-343. Retrieved from http://hhd.fullerton.edu/csa/Research/documents/JonesRikliMaxNoffa 11998Thereliabilityandvalidityofachairsitandreachtest_000.pdf

Kirk-Sanchez, N. J., \& McGough, E. L. (2013). Physical exercise and cognitive performance in the elderly: Current perspectives. Clinical Interventions in Aging, 9, 51-62. https://doi.org/10.2147/CIA.S39506

López-Miñarro, P. A., Sáinz De Baranda, P., Rodríguez-García, P. L., \& Yuste, J. L. (2008). Comparison between sit-and-reach test and V sitand-reach test in young adults. Gazzetta Medica Italiana Archivio per Le Scienze Mediche, 167(4), 135-142.

Monroe, T., \& Carter, M. (2012). Using the Folstein Mini Mental State Exam (MMSE) to explore methodological issues in cognitive aging research. European Journal of Ageing, 9(3), 265-274. https://doi.org/10.1007/s10433-012-0234-8

Morris, T., Osman, J. G., Muñoz, J. M. T., Costa-Miserachs, D., \& Leone, A. P. (2016). The role of physical exercise in cognitive recovery after traumatic brain injury: A systematic review. Restorative Neurology and Neuroscience, 34(6), 977-988. https://doi.org/10.3233/RNN160687

Nakazono, T., Kamide, N., \& Ando, M. (2014). The reference values for the chair stand test in healthy Japanese older people: Determination by meta-analysis. Journal of Physical Therapy Science, 26(11), 1729-1731. https://doi.org/10.1589/jpts.26.1729

Paillard, T. (2015). Preventive effects of regular physical exercise against cognitive decline and the risk of dementia with age advancement. Sports Medicine - Open, 1(1), 16-21. https://doi.org/10.1186/s40798015-0016-x

Pallant, J. (2010). SPSS Survival Manual (4th ed.). Allen \& Unwin Book Publishers.

Petherbridge, D. (2019). Beyond Empathy: Vulnerability, Relationality and Dementia. International Journal of Philosophical Studies, 27(2), 307326. https://doi.org/10.1080/09672559.2019.1594588

Phung, K. T. T., Chaaya, M., Prince, M., Atweh, S., El Asmar, K., Karam, G., Waldemar, G. (2017). Dementia prevalence, care arrangement, and access to care in Lebanon: A pilot study. Alzheimer's and Dementia, 13(12), 1317-1326. https://doi.org/10.1016/j.jalz.2017.04.007

Pinheiro, P. A., Carneiro, J. A. O., Coqueiro, R. S., Pereira, R., \& 
Fernandes, M. H. (2015). "Chair stand test" as simple tool for sarcopenia screening in elderly women. The Journal of Nutrition, Health \& Aging, (November). https://doi.org/10.1007/s12603-0150621-x

Scheltens, N. M. E., Tijms, B. M., Koene, T., Barkhof, F., Teunissen, C. E., Wolfsgruber, S., ... van der Flier, W. M. (2017). Cognitive subtypes of probable Alzheimer's disease robustly identified in four cohorts. Alzheimer's and Dementia, 13(11), 1226-1236. https://doi.org/10.1016/j.jalz.2017.03.002

Seth A. Gale, Diler Acar, K. R. D. (2018). Dementia. Handbook of Clinical Neurology, 159, 303-321. https://doi.org/10.1016/B978-0-444-639165.00019-7

van Alphen, H. J. M., Hortobágyi, T., \& van Heuvelen, M. J. G. (2016). Barriers, motivators, and facilitators of physical activity in dementia patients: A systematic review. Archives of Gerontology and Geriatrics, 66 , 109-118. https://doi.org/10.1016/j.archger.2016.05.008 